\title{
ANADOLU FEVKALADE MÜFETTİŞİ-̇̇ UMUMİİĞİ -IV. Ve V. Damat Ferit Hükümetlerinin Anadolu'daki Yönetimi Büyük Millet Meclisi'nden Geri Alma Teşebbüsü (1920)-
}

Milli Mücadele döneminde son Osmanlı Meclis-i Mebusanı'nın açılması ve Heyet-i Temsiliye'nin istekleri doğrultusunda çalışması İtilaf Devletleri'ni rahatsız etmiști. Özellikle Misak-1 Milli'nin kabulünden sonra, İtilaf Devletleri'nin Istanbul'daki generalleri artık gücün milliyetçi liderlerde olduğunu anlamışlard. Bunun üzerine 16 Mart 1920'de İstanbul işgal edildi. 18 Mart'ta da tutuklanan şahıslar Malta'ya sürüldü. Buna karşılık Heyet-i Temsiliye Başkanı Mustafa Kemal Paşa, 19 Mart 1920 'de Ankara'da "fevkalade selahiyete malik" bir meclisin milletin işlerini yöneltmek ve denetlemek üzere toplanması konusundaki tamimini vilayetlere, livalara kolordu komutanlıklarına gönderdi' ${ }^{1}$. Artık hedef Ankara'da bir meclis toplamak ve bunu bir an önce gerçekleștirmekti. Bu arada İstanbul'da Salih Paşa Kabinesi istifa etmiş (2 Nisan 1920), Damat Ferit dördüncü kabinesini kurmuştu (5 Nisan 1920). Şeyhülislam Dürrizade Abdullah, milli kuvvetleri kâfir ilan eden ve öldürülmelerini vacib gören fetvayı yayınlamışıt². Buna karşı başta Ankara Müftüsü Rifat Efendi tarafından olmak üzere, bu fetvanın geçersizliğini ilan eden pekçok fetva yayınlandi. Anadolu'daki hakimiyeti tamamen kaybetme vaziyetine gelen Damat Ferit Hükümeti, Kuva-yı Milliye'yi ortadan kaldırmak için Kuva-yı İnzibātiye'yi kurdu (18 Nisan 1920). Kuva-yı İnzibatiye, seyyar olarak kurulan askeri birliklerden oluşuyordu. Ancak, Anadolu'da hakimiyeti tekrar tesis edebilmek için askeri alanın dışında da daha geniş yetkilerle donatılmış bir müesseseye ihtiyaç vardı. İște bu kuruluş, Ankara' da BMM'nin açılıp, yönetime el koyduğu bir sırada 28 Nisan 1920'de kurulan Anadolu Fevkalade Müfettiş-i Umumiliği idi. Üyesi.

* Yard.Doç., İstanbul Üniversitesi Edebiyat Fakültesi, Tarih Bölümü Öğretim

1 Mustafa Kemal Atatürk, Nutuk I, İstanbul 1969, s.421.

2 Bu fetva için bakınız; BOA, DUiT, 4-28/21. 


\section{a- Anadalu Fevkalade Müfettişsliği’nin Kuruluşu}

Anadolu Fevkalade Müfettişliği'nin kurulması Damat Ferit'in Sadrazam, Hariciye Nazın ve Harbiye Nazırı Vekili olduğu bir sırada 27 Nisan 1920'de Meclis-i Vükela'da görüşülerek kararlaştırıldı. Bu müfettişlik, Anadolu' da ortaya çıkan istenmeyen durumu bir an evvel ortadan kaldırarak emniyet ve asayişin "serian istikrarına aid tedabiri istikmal vazifesiyle mükellef" olacaktı. Askeriye ve mülkiyede tam bir selahiyete haiz olacak umumi müfettişliğin kararname layihası Meclis-i vükela'ca hazırlanmışt ${ }^{3}$. Bu kararname, Padişah Vahidettin tarafından 28 Nisan 1920 tarihinde imzalanarak Anadolu Fevkalade Müfettiş-i Umumiliği kurulmuştu ${ }^{4}$. Anadolu fevkalade Müfettiş-i Umumiliğinin vazife ve selahiyetlerini düzenleyen kararname de 6 Mayıs 1920 tarihinde Padişah tarafından onaylanmışt1 ${ }^{5}$. Bu kararnameye müzeyyel olarak hazırlanan ve müfettişliğin yetkilerini daha da arttıran bir diğer kararname de 13 Mayıs 1920 'de yürürlüğe girmişti' ${ }^{6}$.

\section{b- Müfettişliğin Kuruluş Amacı}

Damat Ferit Hükümeti tarafından hazırlanan mazbataya göre; müfettişliğin kuruluş amac1 "Anadolu'da tekevvün eden gayr-i mariziyenin bir an evvel izalesi" ile emniyet ve asayişin "serian istikrara" kavuşturulmas1dır $^{7}$. Anadolu Fevkalade Müfettiş-i Umumiliği'nin 28 Nisan 1920 tarihli kuruluş kararnamesine göre, amac1, Anadolu'da emniyet ve asayişi temini hususundaki tedbirleri "istikmal etmek"tir8. Anadolu Fevkalade Müfetiş-i Umumiliği' nin vazife ve selahiyetine dair kararnamede ise bu müfettişliğin kuruluş amac1 "Anadolu' da takrir-i emniyet ve iade-i asayiş”tir?.

Damat Ferit Hükümeti'nin Müfettiş-i Umumiliğin kuruluş mazbatasını hazırladı̆̆ (8 Şaban 1338/27 Nisan 1920) tarihte B.M.M Ankara'da toplantı halindedir. Hükümet tarafından 28 Nisan 1920'den itibaren geçerli olması kararlaştırılan ${ }^{10}$ Müfettiş-i Umumiliğin vazife ve selahiyetlerini düzenleyen kararnamesinin Padişah tarafından tasdiki ise 6 Mayıs 1920 'dir. Bilindiği gibi, BMM, İcra Vekilleri'nin seçilişine dair kanunu 2

3 Meclis-i Vûkala'nın Anadolu'da Fevkalade bir müfettişlik kurulması hakkında 27 Nisan 1920 (8 Şaban 1338) tarihli mazbatası; Başbakanlık Osmanlı Arşivi (BOA), Meclisi Vukela Mazbataları (MV), 254/90.

49 Saban 1338/28 Nisan 1920 tarihli bu kararnamenin metni için bkz; BOA, Nizamat Defteri 30, s. 98.

5 Kararnamenin metni için bkz; BOA, Kavanin 30, s. 106, Anadolu Fevkalade Müfettiss- $i$ Umumiliği kararnamesinin Meclis-i Vükela'ca hazırlanan müsvedddesi için bkz, $M V, 254-98 / \mathrm{A}-1$

6 Kararname metni için bkz; BOA, Kavanin 30, s. 32.

$7 \mathrm{MV}, 254 / 90$

8 Anadolu Fevkalade Müfettiş-i Umumiliği Kuruluş Kararnamesi, madde(m), 1.

9 Anadolu Fevkalade Müfettis-i Umumiliği Kararnamesi (AFMUK), m.1

10 AFMUK, m.9. 
Mayıs 1920'de kabul etmiş ${ }^{11}$ ve BMM'nce seçilen icra Vekiller Heyeti ilk toplantısını Mustafa Kemal Paşa başkanlığında 5 Mayıs 1920'de yapmış$\mathrm{tt}^{12}$. Müfettiş-i Umumi'nin selahiyeti ile ilgili kararnamesinin Padişah tarafından tasdiki, Ankara'daki BMM Hükümeti'nin icraata başlamasından hemen sonradır. Anadolu Müfettiş-i Umumiliğine "muamelat-1 mülkiye ve askeriyede selahiyat-1 kâmile" verilmesi ${ }^{13}$ ve daha önce ve daha önce Kuva-yı Milliye'yi ortadan kaldırmak için kurulan Kuva-yı Inzibatiye'nin "kuva-yı zabıta ve gönüllü kıta" kıtalarının Anadolu Müfettişliği'ne bağlanmas $1^{14}$ dịkkate alındığında, Anadolu Müfettiş-i Umumiliği'nin kuruluş amacının Anadolu'da emniyet ve asayişin sağlanması değil, esasında Ankara'da kurulan Meclis ve hükümetinin ortadan kaldırılması ve İstanbul Hükümeti'nin otoritesini Anadolu'da tekrar tesis etmek olduğunu söyleyebiliriz ${ }^{15}$.

\section{Birim}

c- Anadolu Fevkalade Müfettiş-i Umumiliği'nin Bağlı Olduğu

Anadolu'da sivil ve askeri bütün muamelelerde çok büyük selahiyetlere sahip olan Müfettiş-i Umumilik, sivil ve askeri işlerde ilgili nezaretlerle muhabereye izinli olup doğrudan sadarete "merbut" bir müessese idi $^{16}$. Anadolu Fevkalade Müfettiş-i Umumiliği Kararnamesi'nin hükümlerini icraya koyma vazifesi "Heyet-i Vükela"ya aitti ${ }^{17}$. Müfettiş-i Umumi kendi mesuliyeti altında harcamak ve bilahere hesabını Heyet-i Vükela'ya bildirmek şartıyla "mesture ve gayr-1 melhuze" olmak üzere aylık 20.000 liraya kadar akçe sarf edebilecekti ${ }^{18}$. Kısacası Anadolu Müfettişi, mülki ve askeri olarak doğrudan doğruya Sadaret'e bağlı olduğu gibi bir ayda harcayacağı 20.000 liranın hesabını da bütün mali prosedürün dışında sadace Heyet-i Vükela'ya verecekti. Özellikle, Müfettişin doğrudan Sadaret'e bağlı olması, onu bakanlıkların üzerinde veya en azından bakanların düzeyine çıkarıyordu.

\section{d-Anadolu Fevkalade Müfettiş-i Umumiliği'nin Yetkileri}

Müfettiş-i Umumi, Anadolu'da emniyetin temini ve asayaşin iadesi için askeri ve sivil alanlarda "selahiyet-i kâmileyi haiz" olacakt ${ }^{19}$ Müfet-

11 TBMM Zabut Ceridesi, Devre I, Cilt I, s.185-186.

12 Yusuf Kemal Tengirşenk, Vatan Hizmetinde, İstanbul 1967, s.145.

13 AFMUK m.1.

14 AFMUK, m.2

15 Ankara Bidayet Mahkemesi 4 Temmuz 1920'de Damat Ferit, Dûrrizade Abdullah, Kiraz Hamdi ve sairleri idam cezasına f̧arptırdığı kararında, Müfettis-i Umumiliğin, Ankara hükümetine karşı bütün faaliyetlerin "temin ve tedviri" için kurulduğunu belirtmiştir (Cemil Topuzlu, 80 Yıllık Hatıralarım, Istanbul 1982, s.182).

16 AFMUK m.4.

17 AFMUK, m.9.

18 AFMUK, $\mathrm{m} .8$

19 AFMUK, m.1 
tiş-i Umumi, lüzum gördüğünde deniz kuvvetleri ile bunlara bağlı bütün harbiye ve nakliye gemilerini de kullanabilecekti ${ }^{20}$.

Anadolu'da asayişin temini için lüzum görülecek bütün "kuva-yı askeriye-i inzibatiye, kuva-yı zabıta" ve gönülliu birlikler Müttiş-i Umumiliğin emri altında olacaktı. Müfettiş-i Umumi, bütün bu kuvvetlerin sevk ve idaresinde ve teftişi hususunda yetkili kılınmışt $1^{21}$.

Müfettişlik alanındaki, sivil memurların teftişi de Müfettiş-i Umumi'nin yetkileri içinde idi ${ }^{22}$.

Müfettiş-i Umumi, iktiza eden bölgelerde idare-i örfiyi (sıkıyönetim), ilana ve idare-i örfiye kararnamesi hükümlerine göre muamele yapmaya yetkili idi. Yalnız idare-i örfiye ilanının sebeplerini daha sonra hükümete bildirmesi gerekiyordu ${ }^{23}$.

Müfettiş-i Umumiliğin, icab ettiğinde mevcut askeri teşkilatı ilga ve yeniden Kuva-yı İnzibatiye kurmaya selahiyeti olacaktı. Ancak bu gibi teşkilatın teferruatı, bağlı oldukları makamlarca gerçekleştirilecekti ${ }^{24}$,

\section{e-Müfettiş-i Umumi'nin Kadrosu}

Müfettiş-i Umumiliğin refakatinde askeri yetkilile ${ }^{25}$ dışında mülkiye ve adliyeden de yüksek düzeyde mütehassıs müşavirler bulunacaktı ${ }^{26}$ Ancak Haziran 1920'ya kadar henüz Müfettiş-i Umumiliğin teşkilat ve kadrosunun kurulmadığı görülmektedir ${ }^{27}$.

\section{f- Müfettiş-i Umumiliğin Mâli Kaynakları ve Görevlilerin Maaşları}

Müfettiş-i Umumilik'te görevli şahıslanın maaş, tahsisat, zam ve harcrrahı, bu müfettişliğin kurulmasindan daha önce 18 Nisan 1920 tarihli Kuva-y1 İnzibatiye Kararnamesi ile Harbiye Nezareti bütçesine ilave olunan bir milyon iki yüz on altı bin liralık tahsisattan karşılanacaktı. Anadolu Müfettişliği'nin kurulması için harcanacak 50.000 guruş ile her ay ihtiyaç duyulacak beş bin guruş kırtasiye masrafı da aynı kaynaktan temin edilecekti ${ }^{28}$.

20 AFMU Kararnamesine müzeyyel olarak 16 Mayıs 1336 tarihinde yürürlüğe konan Kararname, (BOA, Kavanin 30), m.1.

21 AFMUK, m.3.

22 AFMUK, m.4.

23 AFMUK, m.5.

24 AFMUK, m.5.

25 AFMUK, m.6.

26 AFMUK, m.1.

27 Zeki Paşa ile yapılan mûlakat, Alemdar, 3 Haziran 1920.

28 AFMUK, m.7. 

cekti.

Müfettiş-i Umumi'ye maaşından başka ayda bin lira tahsisat verile-

Müfettiş-i Umumi'nin refakatinde bulunacak mütahassıslar, erkân, ümera, zabitan ve diğer askeriye mensublarına aylık tahsisatları kadar fevkalade ilave ödeme yapılacaktı. Müfettiş-i Umumilik'te görevli küçük rütbeli subay ve nefarat için de Kuva-yı Inzibatiye Kararnamesine göre asli maaşları dışında harcırah verilecekti ${ }^{29}$.

Müfettiş-i Umumilik emrinde çalıştırılacak harbiye ve nakliye gemilerinin "süvarilerine" aylık 2500 guruş, zabitan ve mühendislere 1500 , gedikli zabitana ise 1300 guruş taamiye verilecekti. Makina efradının maaşı 600 , güverte efradınınki ise 400 guruşa yükseltilecekti ${ }^{30}$.

Müfettiş-i Umumi, yukanıda işaret edildiği gibi, daha sonra hesabını hükümete vermek üzere aylık 20.000 liraya kadar paranın mesture ve gayr-1 melhuze olarak kullanabilecekti ${ }^{31}$.

\section{g-Müfettiş-i Umumi Tayini}

Anadolu Fevkalade Müfettiş-i Umumiliği'nin kurulduğu gün bu müfettişliğe "malumat-1 mülkiye ve askeriyede selahiyet-i kâmileye haiz olmak" üzere Müşir Zeki Paşa'nı ${ }^{32}$ tayini hususunda Padişah'ın iradesi çıkmıştı. Bu tayin aynı gün Sadaret'ten Harbiye ve Dahiliye Nezaretlerine bildirilmişti ${ }^{33}$. Harbiye Nezareti tarafından tesbit edilen ve Anadolu Fevkalade Müfettiş-i Umumiliği'nin Karargâh heyeti kadrosunu gösteren cetvel 14 Şaban 1338/4 Mayıs 1920'de Meclis-i Vükâla'da görüşülerek kabul edilmişsti $\mathrm{i}^{34}$

$\mathrm{Bu}$ arada, İstanbul Hükümeti ilk önce kontrol altına almak istediği İzmit ve çevresi için çalışmalara başlamıştı. İzmit Bölgesi Fevkalâde Kumandanlığı'na tayin edilen Yaver-i Ekrem Süleyman Şefik Paşa'nın vazife, selahiyet ve tahsisatına dair talimatname 15 Saban 1338/5 Mayıs 1920 'da Harbiye Nazırı Vekâleti'nin ${ }^{35}$ teklifi ile Meclis-i Vükelâ' da görüşülmüş, Padişah da talimatnamesinin yürürlüğe girmesine "Meclis-i Vükelẩ karan ile ruhsat" vermişti ${ }^{36}$.

29 AFMUK, m.6.

306 Mayıs 1336 tarihli AFMU Kararnamesine Müzeyyel Kararname, m.2.

31 AFMUK, m.7

32 Hürriyet ve Itilaf Fıkrası yönetim kurulu üyesi olan Zeki Paşa, Balkan ve I.Dünya Savaşı suçlularının yargılandığı mahkeme başkanlığını Anadolu Müfettiş-i Umumiliği görevine tayinine kadar devam etti.

339 Şaban 1338 tarihinde Sadaret Mektubi Kaleminden Harbiye ve Dahiliye Nezaretlerine yazılan tezkere, BOA, Babıali Evrak Odası (BEO), 347146.

98

3414 Şaban 1338/4 Mayıs 1336 tarihli Meclis-i Vûkâla Mazbatası, BOA, MV, 254/

35 Harbiye Nazın Vekili Damat Ferit'dir.

3615 Şaban 1338 tarihli Meclis-i Vûkelâ karan ve irade-i seniye için bakınız, BOA, MV, 254-96. 
18 Saban 1338'de (8 Mayıs 1920), Sadaret, Anadolu Fevkalâde Müfettiş-i Ummumisi Zeki Paşa ile İzmit Havalisi Kumandanı Süleyman Şefik Paşa'lara verilen şifre miftahlarını Dahiliye Nezareti'nden istemi ${ }^{37}$, ancak o ana kadar Zeki Paşa ile Süleyman Şefik Paşa'lara şifre miftahı verilmediği anlaşılmışt ${ }^{38}$.

Müşir Zeki Paşa, göreve başlamasının arkasından bir bildiri yayınlamıştır. Bu bildiride; ecdadın Osmanlı etrafında toplanarak muhteşem bir devlet kurduklarını hatırlatarak, o günkü neslin de yine saltanat ve hilafet etrafında toplanmaları gerektiği ve bu sayede ecdadlarına bir "hayrü'1halef" olduklarını ispat etmelerinin şart olduğunu beyan etmişti. Hz. Adem'den itibaren gelip geçen bütün kavimlerin acılı günleri olduğunu ve "felaketli günlerde reis-i hükümetleri etrafında sımsıkı toplanan kavimlerin yok olmaktan kurtulup yeni bir hayata başladıklarını" ifade eden Zeki Paşa, felaket günlerinde değil "asude zamanlarda bile nifak ve şikak"'n "heyet-i milliye"nin felaketine sebep olduğunu, "nifakçuyâne ihtiras peşinde koşanlar"ın yalnız vatanına, milletine fenalık etmekle kalmayıp İ̉lam nazarında da lanetlendiğini bildirmişti. Hükümet etrafında, esnaf, rençber, asker, memur umum vatandaşların toplanması gerektiği felaketli günlerde "ihtiras peşinde koşanların mutlaka bir ihanet meyliyle Osmanlılığın yok olmasına sebep olacaklarını ve kendisinin de bu gibileri "memleketin selameti namına pençe-i kanuna teslim edeceğini" açıklamişt1 ${ }^{39}$.

İstanbul Hükümeti,Anadolu'da nüfuzunu yeniden kurabilmek için Anadolu Fevkalâde Müfettiş-i Umumiliği'ni tesis edip başına Zeki Paşa'yı 28 Nisan'da tayin etmişti ${ }^{40}$. Zeki Paşa'nın 1 Mayıs'ta durumu inceledikten sonra lüzumlu tedbirleri alacağını söylemesine ${ }^{41}, 4$ Mayıs'ta bildirisini yayınlamasına $a^{42}$ rağmen Haziran başlarında müfettissliğin hâlâ hedefleriyle mütenasip büyüklükte bir kadroya sahip olmadığı anlaşilmaktadır. Anadolu Fevkalâde Umum Müfettişliği'nin kadro ve projesinin tam olarak hazırlanıp hazırlanmadığı hususundaki bir soruya Zeki Paşa; "Müfettiş-i Umumilik kadrosunu lüzumunda ikmal edeceğim. Tasarrufa riayeten şimdilik pek ufak bir kadro ile idare etmektiyim. Şerâit-i selâhiyemizin ağırlığı tahtında icraat-1 vasiada teenni zaruridir" cevabını vermiştit ${ }^{43}$. Yani Zeki Paşa, Müfettişlik ve kadrosunun Anadolu'da istan-

37 Sadaret Mektubi Kaleminden 18 Şaban 1338 tarihinde Dahiliye Nezareti'ne gönderilen tezkereler, BOA, BEO, 347330; BOA, DH-KMS, 59-1/6

38 Dahiliye Nezareti'nden Sadaret'e 9 Mayıs 1336 tarihinde gönderilen cevabi tezkere, BOA, DH-KMS, 59-1/6.

39 Anadolu Fevkalâde Müfettiş-i Umumisi Zeki Paşa'nın bildirisi için bakınız; I'kdam gazetesi, 5 Mayıs 1920.

40 Alemdar, 29 Nisan 1920

41 Aksam, 1 Mayıs 1920.

42 İdam, 5 Mayıs 1920.

43 Zeki Paşa ile yapılan mülâkat için bakınız; Alemdar, 3 Haziran 1920. 
bul yönetimini tékrar tesis edebilecek kadar güçlenmediğini ifade ediyordu. meleri

h- Müfettiş-i Umumi Zeki Paşa'nın Ankara Hükümeti ile Görüş-

Anadolu'da İstanbul Hükümeti'nin otoritesini tesis etmeye çalışan Zeki Paşa, Binbaşı Recep Sezai Bey aracılığı ile Mustafa Kemal Paşa ile irtibata geçmişti. Binbaşı Recep Sezai Bey, Zeki Paşa'nın iki mektubunu Ankara'ya ulaştırmıştı. Zeki Paşa, 28 Mayıs 1920'de Mustafa Kemal'e gönderdiği ikinci mektupta, O'nun vatanseverliğinden ve askerlikteki başarılarından takdirle söz etmiş, fakat barışın tesis edilmeye çalışıldığı bir dönemde, merkezi hükümete yani İstanbul hükümetine karşı gelinmemesi ve müslümanlar arasında kan dökmeye sebep olacak hareketlerden kaçınılması gerektiğini belirtmişti. Bunun yanı sıra Zeki Paşa'nın Ankara hükümetinden bazı istekleri vardı. Bu istekler şunlardır;

- Memleketin menfaatleri hesabına, resmi ve yasama yetkisi olmayan Büyük Millet Meclisi feshedilmelidir.

- Büyük Millet Meclisi tarafından kurulan Vekiller Heyeti, yani Ankara Hükümeti ilga edilmelidir.

- Anadolu'daki bütün askeri birlikler, milli teşkilatlar ve yönetim, merkezi hükümete yani İstanbul Hükümetine itaat etmelidir.

- Bu meselelerin detaylarını görüşmek üzere Ankara'nın tayin edeceği delegelerle görüşmeler yapılacaktır. tir.

- Görüşmelerden bir netice alana kadar operasyonlara ara verilecek-

Bunların dışında Zeki Paşa, genel bir afvın ilanı ve Mustafa Kemal Paşa'ya eski rütbe ve itibarın iadesi için arabuluculuk yapabileceğini Mustafa Kemal Paşa'ya bildirmişti. Zeki Paşa, İstanbul-Hükümeti'nin memleketin hayati menfaatleri karşısında yurtseverlik şuuruyla hareket ettiğini, tekliflerinin Ankara tarafından kabul edilmemesi halinde karşılaşacağı sonuçtan Mustafa Kemal Paşa'ların sorumlu olacaklarını ayrıca açıklamıştı. Zeki Paşa, kaybedecek zamanın olmadığını ve acilen cevap verilmesini istemişti $\mathrm{i}^{44}$.

Bunun üzerine; BMM Hükümeti'nin Genel Kurmay Başkanı İsmet İnönü tarafından 30 Mayıs 1920'de cevap verilmiştir. BMM, İstanbul Hükümeti'nin uzlaşma tekliflerinin doğrusunu, esas niyetlerini anlamak için 5 Haziran 1920'de Bursa-Çekirge'de görüşme yapılmasına karar vermişti. Ankara Hükümeti, İstanbul'dan heyetlerin gelebilmesi için ikinci bir

44 Zeki Paşa'nın Mustafa Kemal Paşa'ya yazdığı 28 Mayıs 1920 tarihli mektup için bakınız; Bilal Şimşir, Ingiliz Belgelerinde Atatürk (1919-1938), Ankara 1975, s. 128-130. Zeki Paşa'nın teklifleri ve BMM Hükümetinin tutumu için ayrıca bakını, Şimşsir, a.g.e., s.142-143. 
emre kadar Adapazarı, Sapanca ve İzmit bölgesinde askeri faaliyetleri durdurmuştu. Çekirge görüşmelerinde Ankara yönetimini şu şahıslar temsil edecekti;

- Albay ismet (İnönü) - Heyet Başkanı

- Topçu Binbaşı Refet,

- Kırşehir Müftüsü Recep Efendi,

- Sivas Milletvekili Necati,

- İbrahim Efendi, Teğmen, Emir Subayı,

- İsmail Hami, Sekreter,

Görüşmeyi kabul eden Ankara yönetimi, BMM'nin varlığı ve faaliyet serbestisi konusunda rezerv koymus, Zeki Paşa'nın BMM'ni kapatma ve Vekiller Heyeti'ni ilga etme şartını dikkate almamıştı ${ }^{45}$.

Neticede Zeki Paşa'nın Ankara ile görüşme ve anlaşma çabası başarisızlıkla neticelendi ${ }^{46}$.

l- Anadolu Fevkalâde Müfettiş-i Umumiliği'nin Ortadan Kaldırnllș

Ankara Hükümeti'nin Anadolu'da yönetime tam olarak sahip olması ve özellikle Doğu Cephesi'nde başarı göstermesi üzerine İtilaf Devletleri'nin Ankara Hükümeti hakkındaki düşüncelerinin değişmeye başladığını görüyoruz. İtilaf Devletleri, bir taraftan İstanbul yönetimince parafe edilen Sevres Andlaşması'nı İstanbul Hükümeti'ne tasdik ettirmeye uğraşrken diğer taraftan da İstanbul Hükümeti'nin Ankara Hükümeti ile anlaşması hususunda bir heyetin İstanbul'dan Anadolu'ya gönderilmesini istiyorlardi ${ }^{47}$. Bu arada Ankara İstiklal Mahkemesi Büyük Millet Meclisi'nin müsaadesi olmaksızın İtilaf Devletleri ile müzakerelere girișen ve Sevres'de Sevres Anlaşması'na imza koyan Damat Ferit, Hâdi Paşa, Rıza Tevfik ve Reşat Halis hakkında gıyaben idam kararı vermişti (7 Ekim $1920)^{48}$. Aynı gün İstanbul'daki İngiliz, Fransız ve İtalyan Yüksek Komiserleri Sadrazam Damat Ferit'e ortak bir nota vererek Anadolu'ya bir heyetin gönderilmesini istemişlerdi ${ }^{49}$. Ankara Hükümeti kabul etmedikten sonra herhangi bir barıșın sağlanamayacağını anlayan İtilaf Devletleri'nin görüşleri doğrultusunda yeni bir hükümetin kurulabilmesi için Damat Ferit'in görevden ayrılması gerekiyordu. Bu amaçla İstanbul'daki İtilaf

45 Ankara Hükümeti Genel Kurmay Başkanı Albay Ismet'in 30 Mayı 1920 tarihli mektubu için bkz; Şimşir, a.g.e., s. 130-131.

46 Simsir, a.g.e., 175

47 Bilal N.Şimşir, Ingiliz Belgelerinde Atatürk (1919-1938), C. II, Ankara, 1975, s. $359,361,367$.

48 Ergün Aybars, Istiklal Mahkemeleri, İzmir 1988, s.56.

49 Şimşir, a.g.e., s. 369-370. 